\title{
Advanced noninvasive ventilation course: the participants' view
}

In November 2015, ERS held its first advanced noninvasive ventilation course. Here, two participants give their views of the course.

\section{Lusinda Dushi, Albania, a participant}

Patients with respiratory failure often have a dramatic presentation. Since working as a resident, I have been overwhelmed by the challenges of respiratory acute conditions. My hospital "Shefqet Ndroqi", Tirane has been equipped in recent years with bilevel positive airway pressure and continuous positive airway pressure ventilation, but a lack of knowledge and experience has limited the possible benefit to patients.

The NIV advanced course was an excellent opportunity not only to refresh my basic knowledge, but also to advance it with the most recent studies in this domain of chest medicine. I was impressed by the amount of data and studies published in recent years. For instance, it was very important to gain a good understanding of the uses of NIV in acute settings like hypoxic respiratory failure, pulmonary oedema or massive bilateral pneumonia, while its use in unilateral pneumonia remains controversial. Other uses, for example in the postoperative setting, neuromuscular disorders like amyotrophic lateral sclerosis and Duchenne, and obesity are important applications.

The second day was even more productive focused on the practical aspects of NIV and the different equipment available (e.g. different masks). Taking a close look at these tools gave me more insight into the applicability of NIV.

The atmosphere was very friendly. The speakers impressed me with their kindness and humility;

\section{About the course}

Venue: Milan, Italy

Date: November 5-6, 2015

Course organisers: Stefano Nava, Paolo Navalesi, Anita K. Simonds

Faculty: Fekri Abroug, Miguel Ferrer, Miguel Gonçalves, Leo Heunks, Stefano Nava, Paolo Navalesi, Paolo Pelosi, Anita K. Simonds, Peter J. Wijkstra, Wolfram Windisch

ERS members can access materials from this course at ers-education.org/events/courses To find out more about ERS's range of courses visit ersnet.org/education/courses The next NIV basic concepts course will take place in Hanover, Germany, on February 2-3, 2017. The ERS Practical Handbook of Noninvasive Ventilation, edited by Anita K. Simonds, is available from www.ersbookshop.com 
their simple language; and their ability to translate complicated charts and figures into simple, practical knowledge. I also appreciated the contact with other participants. They were friendly and I could share my own experience and learn from theirs. The breaks were nicely arranged and allowed for a moment "to take a breath" and start over.

\section{Dewi Nurul Makhabah, Indonesia, a participant}

This course allowed me to gain experience of new tools and to share knowledge with participants from different disciplines. The interesting and lively discussions provided a lot of new insights and knowledge sharing, making the course a very good experience. One of the controversial issues discussed was whether neurally adjusted ventilatory assist (NAVA) mode ventilation can be considered NIV: some of the participants disagreed with the speaker, viewing NAVA as mechanical ventilation when nasogastric tube insertion is required.

The important of the interface in NIV was one of the major things I learnt from the course. This was very interesting for me since in Indonesia the supply of interfaces is limited. The section on cough manipulation was also very good experience, since in my hospital we are not familiar with its use. 